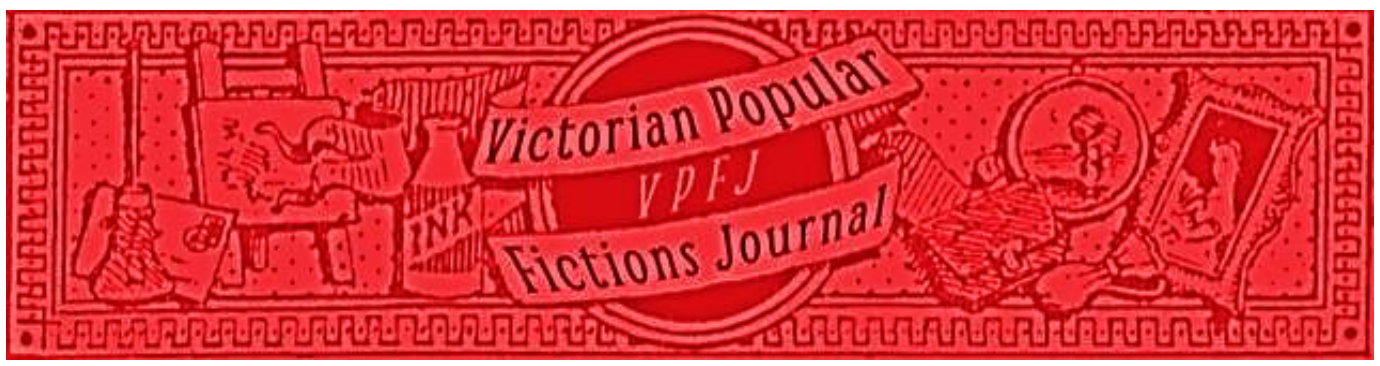

\title{
Nick Murphy (dir.), A Christmas Carol (TV Mini-Series). UK/USA: FX Productions, Scott Free Productions, Hardy Son \& Baker, BBC, 2019
}

\section{Reviewed by Emily Bell}

To begin with: Nick Murphy's mini-series adaptation of A Christmas Carol opens with a boy urinating on a gravestone, the heat of it melting the snow covering the stone's face to show that yes, Marley is dead. Nevertheless, it trickles down to the corpse, animated in his coffin, begging for peace in a scene that more closely invokes Alfred Tennyson's representation of madness and death in "Maud" (1855):

DEAD, long dead,

Long dead!

And my heart is a handful of dust,

And the wheels go over my head,

And my bones are shaken with pain,

For into a shallow grave they are thrust,

Only a yard beneath the street,

And the hoofs of the horses beat, beat,

The hoofs of the horses beat,

Beat into my scalp and my brain,

With never an end to the stream of passing feet,

Driving, hurrying, marrying, burying,

Clamour and rumble, and ringing and clatter,

And here beneath it is all as bad,

For I thought the dead had peace, but it is not so;

To have no peace in the grave, is that not sad?

But up and down and to and fro,

Ever about me the dead men go;

And then to hear a dead man chatter

Is enough to drive one mad. 
From its opening shots, it is clear that this Christmas Carol, broadcast on BBC One in three parts from the 22-24 December 2019, is treading very un-Dickensian territory. This is Dickens's Christmas story as "psychological realism" (Mangan 2019), stripped not only of its humour but also of much of its language, structure, and story. New ground is covered here: this is possibly the first TV adaptation of the Carol to be episodic, and it provides backstory and explanation where Dickens only alludes.

Guy Pearce plays Scrooge as methodical, more interested in animal lives than human ones, with a flawless memory for numbers. This comes across as a slightly lazy indication of autism or other neurodivergence. The potential implicit in this choice, as with many interesting ideas in this adaptation, is gestured at but not fully explored. Moreover, the wider emphasis on horror, alongside a climax that emphasises that Scrooge cannot and should not be forgiven, makes the viewer feel as if Scrooge were being punished for his divergence. This thread gets buried in a list of factors intended to explain, but not excuse, his actions. Instead, this adaptation dedicates much of its three episodes to Scrooge's past, as a child and as a businessman, and Marley's experiences in the afterlife. Nonetheless, Scrooge's interest in numbers also functions as a recognition, in the wake of the introduction of the census, of a new Victorian interest in counting and quantifying; the series brandishes its Victorian realism in surprisingly attentive ways.

This Carol is inconsistent in its relationship with the past, both dismissive and yet more interested in it than in the present and future: in showing the poverty of the Cratchits and the familial discord Scrooge has sown, the Ghost of Christmas Past retorts angrily to Scrooge "It is not about you!", but writer Steven Knight is clearly very invested in Scrooge's past, dedicating more than two of the three episodes to it. As such, the series suffers from an underlying tendency to overexplain and is somewhat bloated by its own ambitions, fleshing out things Dickens did not, but not always to the benefit of the story or the viewer. Marley's time in the afterlife, while visually stunning, does little to advance the rest of the story. I am similarly unconvinced that we needed to see the forging of the chains themselves, when the power of Dickens's text is in the sudden realisation of what they are and what they mean for Scrooge. Scrooge too suffers from a need to overexplain here, monologuing to Cratchit and the ghost of Marley (and also monologuing to explain his monologuing). These dialogue-heavy moments don't take advantage of $\mathrm{TV}$ as a visual storytelling medium, although the cinematography of the series is very effective, with powerfully frosted scenes and sparse interiors.

Nevertheless, some of the engagement with Dickens's Carol and Victorian literature and culture more broadly is achieved with great subtlety and nuance, as with the invocation of Tennyson mentioned above. Scrooge's recognition of Marley's face in the doorknob, often an exaggerated moment in adaptations of the story, is delicately done - up to the point when we are shown, rather gruesomely, that the knocker, and thus the ghost of Marley, has lost his jaw. The presence of Ali Baba is a thoughtful and effective use of the Dickensian text, picking up on a passage often entirely overlooked: 


\begin{abstract}
"The Spirit touched him on the arm, and pointed to his younger self, intent upon his reading. Suddenly a man, in foreign garments: wonderfully real and distinct to look at: stood outside the window, with an axe stuck in his belt, and leading by the bridle an ass laden with wood.

'Why, it's Ali Baba!' Scrooge exclaimed in ecstasy. 'It's dear old honest Ali Baba! Yes, yes, I know! One Christmas time, when yonder solitary child was left here all alone, he did come, for the first time, just like that."”
\end{abstract}

(Dickens 1843: stave 2)

Audience members took to social media to complain about the character's presence, as well as bemoaning the swearing which is rife in the series. These reactions show the significance of this adaptation, both in the minute attentiveness to the text and its departures from it. This is not the comfortable Dickens viewers clearly expected, flattened down to recognisable features across decades of adaptations, instead yielding a kind of raw power that perhaps brings us closer to the source text's original impact, intended as it was as "a Sledge hammer" to convey the horrors of childhood poverty (Dickens [1843] 1974: 461).

The series is notably irresponsible in its treatment of historic sexual abuse, showing an abused child enacting abuse onto others, throwing in his face the love and family he has subsequently lost, and denying him any redemption. "This excuses - this explains me", Scrooge says, in an effort to escape judgement. While the point is clearly intended to be that it is in each individual's power to move on and that there is no true excuse for Scrooge's subsequent actions, forcing someone to confront their sexual abuse as a child and then reprimanding them for not recognising simultaneously that they were loved feels unnecessarily cruel. And this is where the key divergence from Dickens comes, not only in story and language, but in spirit. Dickens's Christmas Carol resolves itself upon the redemptive power of kindness. Scrooge's stubborn refusal of it as the ghosts work their magic is part of the wonderful humour of Dickens, also missing from this adaptation, but ultimately this new Carol shows a cycle of trauma and abuse that results in Scrooge not being able to be redeemed, because he could not overcome his own abuse. Although the death of Tiny Tim, portrayed very differently here, can be undone, there are countless deaths and tragedies that cannot.

However viewers resolve these problems within themselves, what the complexities and ambiguities of this adaptation do effectively is to restore a strong feeling of anger and injustice, right to the closing act (which, on the whole, follows more of the beats of the source text). Watching a distressed Mrs Cratchit (played with quiet dignity by Vinette Robinson) as she seeks some control in her own household by insisting, in vain, that Scrooge leave, provides a distressing end; Scrooge does not expect, nor ask for, forgiveness, and he is not comfortably assimilated into a story of Victorian moral improvement. The attempts to make this a story for our times sometimes work, and sometimes do not; the factory fire in Scrooge's past brings Grenfell to mind, and the revelation that his manipulation of Mrs Cratchit is the cause for the spirits' visits speaks to us in the age of \#MeToo retribution. Although it is a successful story of societal wrongs that need to be righted and the abuses of men in power, it loses something of its wider 
applicability, calling for resistance instead of self-reflection. Marley's chains, which we see being forged, represent the lives lost in the factories and mines of the company of Scrooge \& Marley, rather than the chains we all forge in life. Nonetheless, the closing image of Mrs Cratchit, looking out into the London street then directly at the camera to declare "Spirits, past, present and future: there is still much to do", is a powerful call to arms.

\section{Bibliography}

Dickens, Charles. 1843. A Christmas Carol. London: Chapman \& Hall.

Dickens, Charles. [1843] 1974. The Letters of Charles Dickens. Vol. 3. Edited by Madeline House, Graham Storey and Kathleen Tillotson. Oxford: Oxford University Press.

Mangan, Lucy. 2019. "A Christmas Carol review - twee-free torment-fest is a tonic for our times." The Guardian, (22 December), https://www.theguardian.com/tv-andradio/2019/dec/22/a-christmas-carol-review-twee-free-torment-fest-is-a-tonicfor-our-times.

Tennyson, Alfred. 1855. Maud and Other Poems. London: Edward Moxon and Co.

\section{Recommended Citation}

Bell, Emily. 2020. Review of Nick Murphy (dir.), A Christmas Carol (TV Mini-Series). UK/USA: FX Productions, Scott Free Productions, Hardy Son \& Baker, BBC, 2019. Victorian Popular Fictions Journal 2.1: 116-119.

DOI: https://doi.org/10.46911/EYLB6649 